\title{
\begin{tabular}{c|c|c|}
\hline IDUNAS & NATURAL \& APPLIED SCIENCES & 2020 \\
& Jol. 3 \\
No. 2 \\
$(13-33)$
\end{tabular}
}

\section{Bioinks for Bioprinting Tissues and Organs}

\author{
Review Article \\ Yağmur Can ${ }^{D}$, Rümeysa Karaca ${ }^{(D)}$, Funda Özbek ${ }^{(D)}$, Gizem Boz ${ }^{i}$, Açelya Yılmazer ${ }^{(D)}$, Pınar Yılgör Huri ${ }^{1 *}$ (iD \\ ${ }^{l}$ Department of Biomedical Engineering, Faculty of Engineering, Ankara University, Ankara, Turkey \\ Author E-mails \\ phuri@ankara.edu.tr \\ *Correspondance to: Assoc. Prof. Dr. Pinar Yilgor Huri, Department of Biomedical Engineering, Faculty of \\ Engineering, Ankara University, Ankara, Turkey \\ Tel: +903126000100 \\ DOI: $10.38061 /$ idunas. 782768
}

Received:20.08.2020; Accepted:20.11.2020

\section{Özet}

Üç boyutlu (3B) baskı teknolojisinin kullanılması, doku mühendisliği ve rejeneratif tıptaki uygulamaları büyük ölçüde etkilemiş̧ir. Özellikle, biyobaskı alanındaki son gelişmeler, canlı ve fonksiyonel doku ve organların üretimi için umut vadetmektedir. 3B biyobaskı, dokuların katman-katman üretiminde biyomürekkeplerin kullanılmasını içerir ve gerekli şekli sağlamak, hücre fonksiyonlarını ve canlılı̆̆ını korumak gibi önemli rollere sahiptir. Biyomürekkepler, doğal veya sentetik kökenli biyomalzemelerdir ve hücrelerin yeni doku oluşturmak için çoğalmaları ve farklılaşmaları için doğal hücre dışı matris ortamını taklit ederler. $\mathrm{Bu}$ derlemede, 3B biyobaskı yöntemi ve biyomürekkep çeşitleri ile biyobaskı alanındaki kilometre taşı uygulamalar ayrıntılı olarak incelenmiştir.

Anahtar Sözcükler: 3B bask1, Biyomürekkep, Hidrojel, Doku Mühendisliği, Rejeneratif Tıp

\section{Abstract}

Compared to the other imaging modalities Magnetic Resonance Imaging (MRI) system has many the use of three-dimensional (3D) printing technology greatly impacted the applications in tissue engineering and regenerative medicine. Especially, recent developments in the bioprinting field holds promise for the production of viable and functional tissues and organs. 3D bioprinting process involves the use of bioinks in the layer-by-layer production of tissues and has such important roles as providing the shape and preserving the cell function and vitality. Bioinks are biomaterials, of natural or synthetic origin, and they mimic the natural extracellular matrix environment for cells to proliferate and differentiate into to form the new tissue. In this review, 3D bioprinting methods and types of bioinks are discussed in detail, with special emphasis on the milestone applications in the bioprinting field.

Keywords: 3D bioprinting, Bioink, Hydrogel, Tissue engineering, Regenerative medicine 


\section{INTRODUCTION}

3D bioprinting is a promising technology to fabricate variety of tissues and organs in the laboratory using cells and biomaterials. Emerging as a new biofabrication method, 3D bioprinting has significant control over reproducible tissue structures. Homogeneous seeding and growth of the cells within 3D structures, which is among the difficulties encountered in tissue engineering technique, can be surmounted with the bioprinting method. Also, with this technique, various cell types can be delicately positioned to specific locations within complex 3D structures and it is possible to reach high cell densities. Bioprinting is performed with materials containing live cells. These materials, called bioinks, are biocompatible hydrogels that form a gel in accordance with some external stimuli fine-tuned according to the bioprinting technique used (such as chemical cross-linking, photo cross-linking etc.). Bioinks are designed to mimic the extracellular matrix environment structurally and mechanically and they promote the cell adhesion, proliferation and differentiation. These polymer-based matrices should be able to form a highly stable gel since this is needed to obtain high printing accuracy.

There are four different types of bioprinting techniques, and each technique has strengths and weaknesses. For instance, in extrusion printing, which is the most suitable technique in terms of vertical configuration, cell viability and printing speed are lower than other techniques. Stereolithography has the fastest printing speed among other techniques, and due to this feature, it protects cells from nonphysiological conditions. The bioink to be selected for each bioprinting technique contains different requirements. Bioinks are generally developed from natural or synthetic biomaterials or from a combination of these materials. An ideal bioink should have appropriate mechanical, rheological and biological properties to perform the function of a tissue and organ. The selection of bioink is critical because its properties are essential for printability, including achievable structural resolution, shape stability and cell viability before, during and after gelling (Güngör-Özkerim, İnci, Zhang, Khademhosseini \& Dökmeci, 2018; Kačarević et al., 2018). In this review, recent developments in the bioprinting technology are examined and summarized by focusing on various bioprinting techniques and bioink properties.

\section{What is a Bioink?}

3D printing, which has recently emerged as a rapid fabrication technique, is a method that gains great importance day by day. 3D printing is a technique that has many different processes and are frequently used in the production of functional tissues and organs. Bioprinting method provides the opportunity to place various cell types on the printed tissue scaffolds. Scaffolds with a suitable microarchitecture should be produced and also the effect of production on cell viability should be taken into account. Bioprinting can be performed clinically in different environments to satisfy the need of a patient with damaged tissue. The application steps of the bioprinting technique in the clinical setting are shown in Figure 1 (Güngör-Özkerim et al., 2018; Kačarević et al., 2018). 


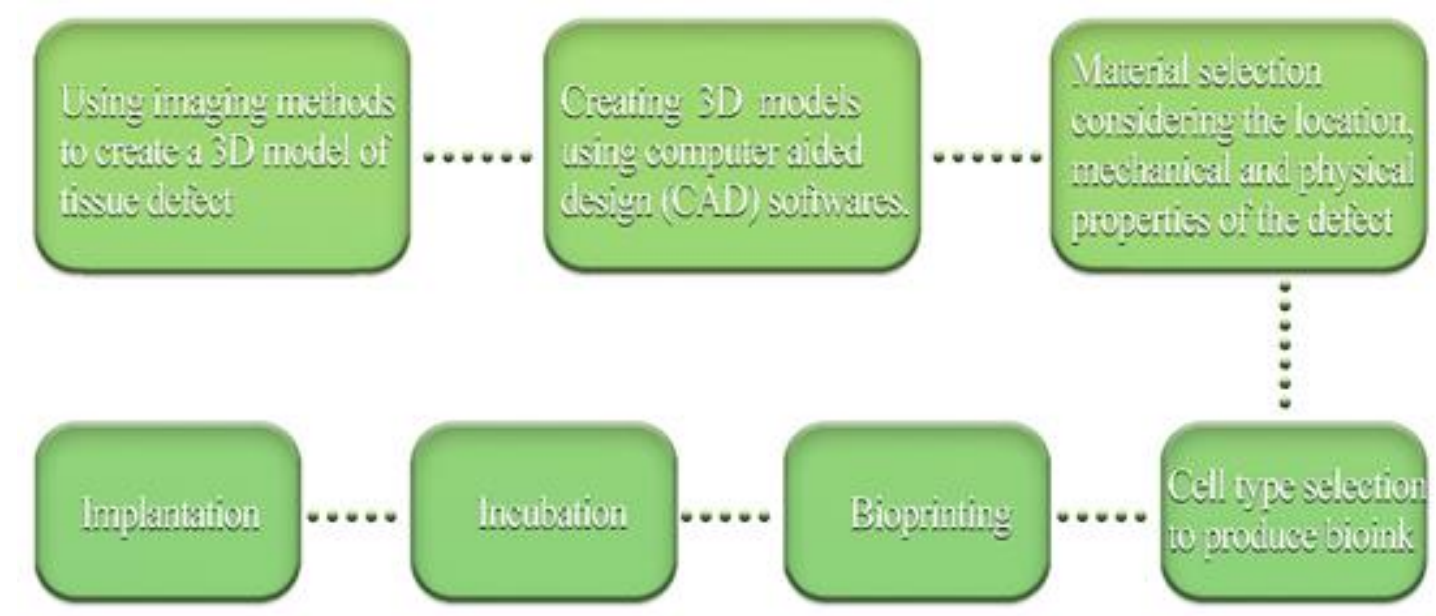

Figure 1. Stages of bioprinting in clinical applications. Digital 3D images are used by various softwares to design the appropriate scaffold. Bioprinting process is performed after selecting the appropriate material and cells for the application. The 3D culture which is obtained from incubation is evaluated for implantation by various methods.

The aim of bioprinting is to present a new method to tissue implants and to minimize the process by eliminating the problems of the patients who can have difficulties in this process. In addition, it is to prevent animal experiments used in therapeutic tests. Furthermore to the advantages and challenges of each technique, the current research status for the various tissue types of each technique is addressed. These four techniques have been observed to have various effects on cell viability, resolution, and printing accuracy. Additionally, a significant effect of material selection and concentrations on printing properties was observed (Kačarević et al., 2018). Figure 2 summarizes the process of bioink formation for bioprinting.

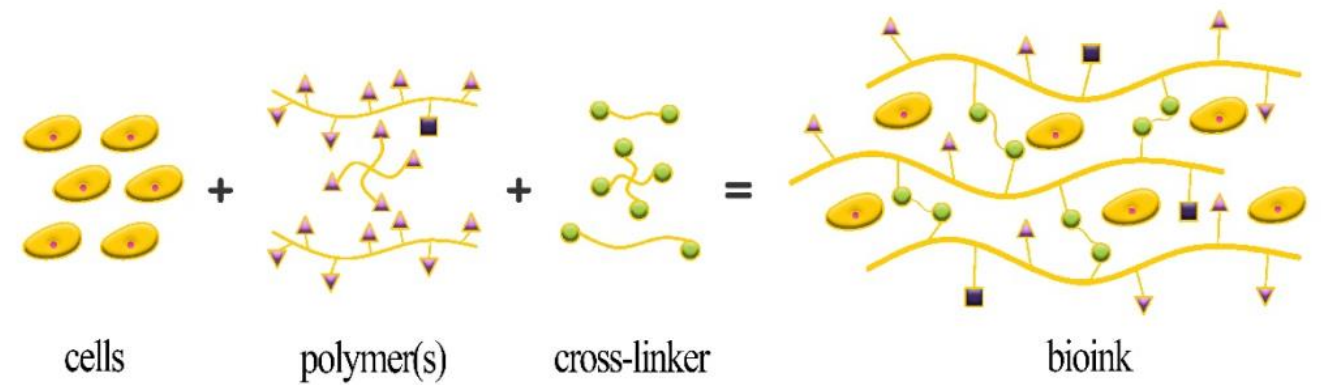

Figure 2. Bioink formation for 3D bioprinting. Bioinks are formed by the combination of cells and polymers. They are then used to print 3D tissues.

\section{GENERAL FEATURES OF BIOPRINTING TECHNOLOGIES}

\section{Inkjet-Based Bioprinting}

Inkjet bioprinting has two types, thermal based inkjet printing and piezoelectric elements which is the first printer used to print live cells. Some problems were encountered while developing inkjet bioprinting. The first of these problems is that the cells die due to drying on the substrate during printing. As a result of the studies, it was seen that the problem was solved by trapping the cells in a polymer structure. Thus, studies on cell-containing hydrogels have increased and new developments have been obtained. Now, the exact positioning of the cells can be achieved with inkjet bioprinting. 
As seen in Figure 3, there are two types of inkjet bioprinters, one using a thermal actuator and one with a piezoelectric actuator. Thermal-based inkjet printing uses an element (heater) heated from $100^{\circ} \mathrm{C}$ to $300^{\circ} \mathrm{C}$ to nucleate a balloon. Since the balloon causes an increase in pressure in the head, it allows the droplets to be sprayed from the mouth. It does not harm the cells since it does not use low temperature and is not used for a long time.
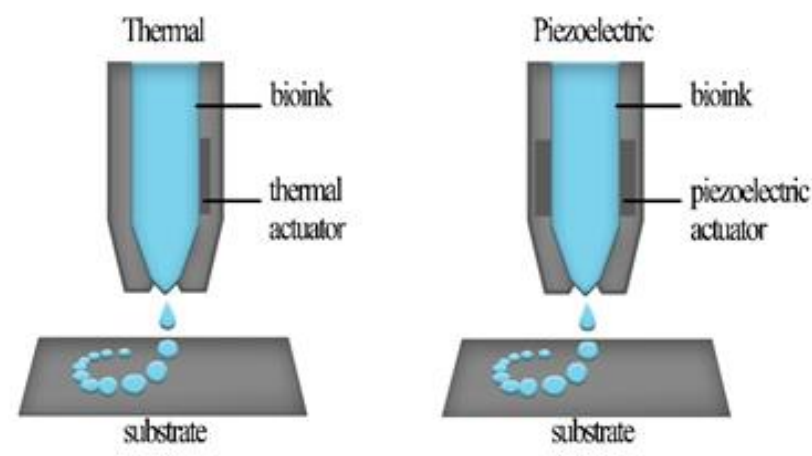

Figure 3. Schematic diagram of inkjet bioprinting.

The piezoelectric inkjet printer needs waves to extract the liquid from the mouth. These waves are acoustic waves and use piezoelectric crystals for their formation. A problem encountered when using this technique is that the viscosities of the mechanism limits the use of high-concentration and viscous bio-inks, as they reduce the acoustic/pressure waves applied and prevent the droplets from ejecting. There are some parameters to consider for the production of three-dimensional structures. The two most important parameters in inkjet printing are concentration and surface tension. While more functional structures are produced with high concentration solutions, opposite structures are formed in low concentration.

In the Table 1, some parameters of inkjet printing and their values are specified. As seen, these low cost printers have a great value in terms of cell viability. However, besides these advantages, it has some limitations in terms of cell packaging due to its inks not having high concentrations. (Hölzl et al., 2016; Kačarević et al., 2018).

Table 1. Overview of important bioink parameters for inkjet-based bioprinting.

\section{Inkjet-based bioprinting}

\begin{tabular}{cc}
\hline Parameters & Values \\
\hline Viscosity & $<10 \mathrm{mPas}$ \\
Cell density & Low $<10^{6}{\text { cells } \mathrm{ml}^{-1}}^{-10-50 \mu \mathrm{m}}$ \\
Resolution & Low \\
Single cell control & Fast \\
Speed & $<85 \%$ \\
Cell viability & \\
\hline
\end{tabular}




\section{Laser-based bioprinting}

Laser-based bioprinting is one of the nozzle-free bioprinting methods that uses a laser to push cells from a solution to the surface. The basic principle is to create a pulse on the absorbent surface using a focused laser. The laser heats some of the solution so that some of the bioink is pushed towards the surface with the help of the air pocket. Its main advantage is that it does not contain nozzles and it can use high viscosity materials. But when printing on these printers, it is necessary to pay attention to the heat because high temperature can damage the cells. Figure 4 shows the elements of laser-based bioprinting and gives information about the working principle.

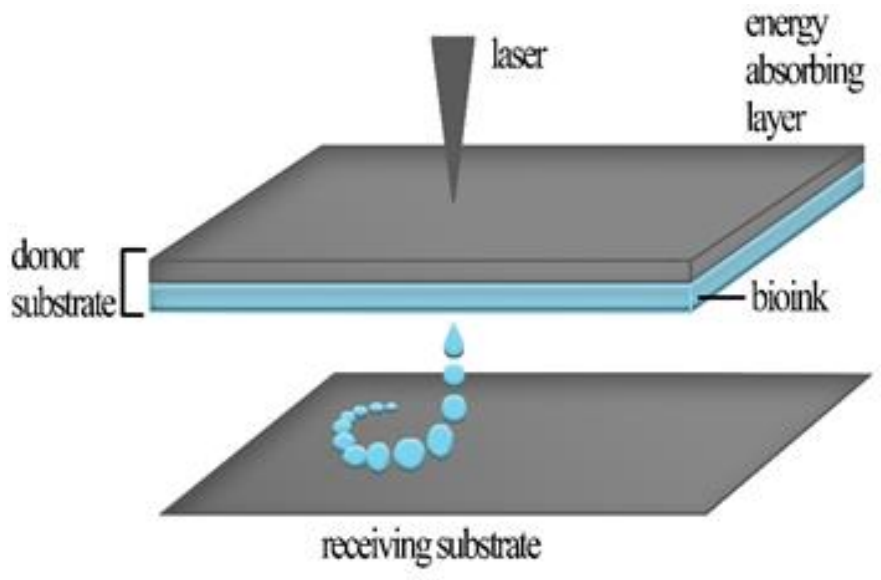

Figure 4. Schematic of laser-based bioprinting technique.

The most important advantage of laser-based bioprinting is that it is not affected by shear stress. However, there are some parameters that are specific for this technique. Viscosity and temperature are the two most important of these and are among the factors that play an important role in 3D tissue formation (Table 2) (Hölzl et al., 2016; Kačarević et al., 2018).

Table 2. Overview of important bioink parameters for laser-based bioprinting.

\section{Laser-based bioprinting}

\begin{tabular}{cc}
\hline Parameters & Values \\
\hline Viscosity & $1-300 \mathrm{mPas}$ \\
Cell density & Medium \\
Resolution & $10-100 \mu \mathrm{m}$ \\
Single cell control & Medium \\
Fabrication speed & Medium \\
Cell viability & $>95 \%$ \\
\hline
\end{tabular}




\section{Extrusion-Based Bioprinting (Fused Deposition Modeling)}

In extrusion based printing, which is one of the most preferred methods for the production of 3D models, bioink is placed in disposable syringes and dispensed with a nozzle by pneumatic or mechanical pressure (Figure 5). It can distribute high viscosity bioink by providing more control with screw based accumulation. Briefly, the working principle is as follows. After the filament fed from the coil inside the system is accumulated, the print head is guided according to the tissue structure to be created with the help of a computer. The print head, which moves horizontally to create the first layer, is then moved vertically to create a new layer. The control of the head is completely personal and its speed can be adjusted according to the state of the print.
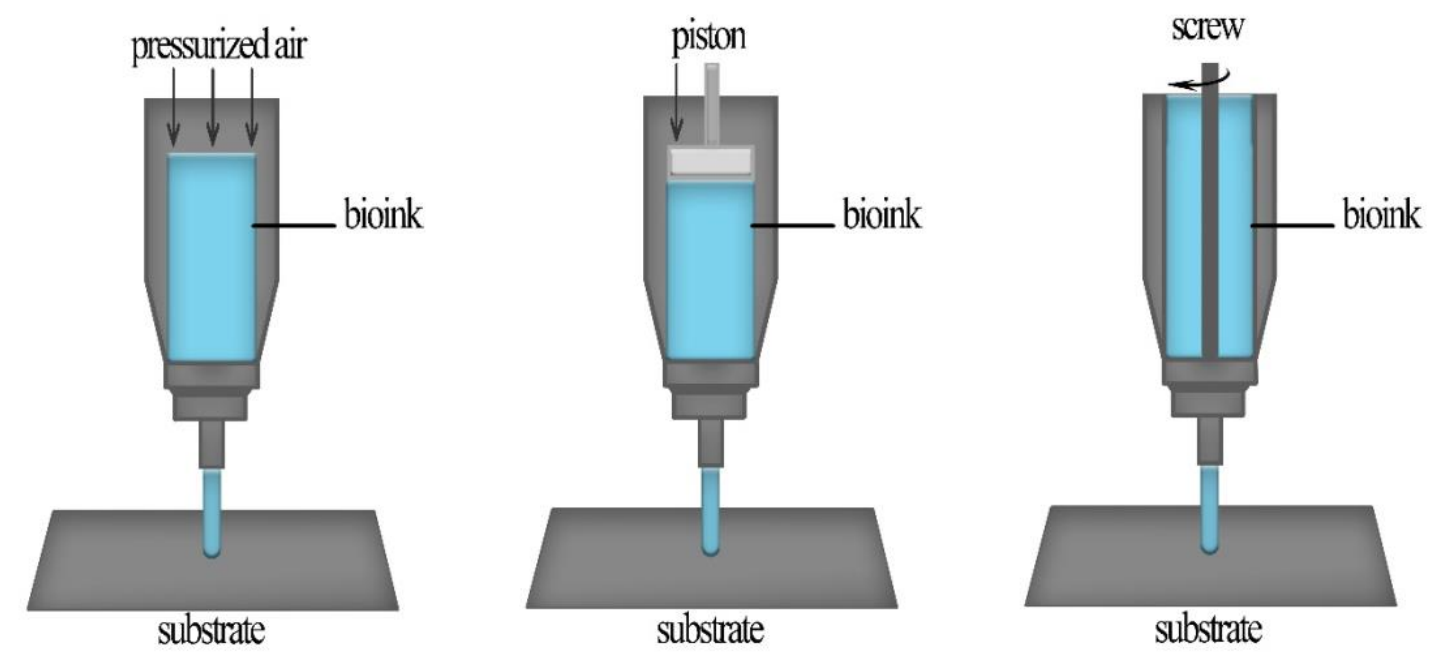

Figure 5. Working principle of extrusion-based bioprinting.

Extrusion-based printing has some disadvantages. It has lower resolution compared to other bioprinting techniques. This feature is an undesirable limitation for functional tissue formation. Also in bioprinting methods, low pressure drops are desired to prevent cell viability from being damaged and cell deaths, but this technique cannot provide them. Therefore, studies should be carried out to make sure that the hydrogel provides the necessary qualities before hydrogel printing. Hydrogels with low viscosity and additives should not be used. Extrusion-based printing is also very important in the rheological behavior of bioink. Viscosity of bioinks generally change with cutting speed. However, increased viscosity causes more cell deaths. Therefore, the concentration of the combination of bioink and biomaterial must be well adjusted. Otherwise, cell deaths cannot be prevented and the desired functional tissue cannot be obtained (Hölzl et al., 2016; Kačarević et al., 2018).

\section{Stereolithography}

Stereolithography, the oldest 3D printing technology, is based on the technique of curing the liquid photopolymer in a boat with a low power ultraviolet (UV) laser. SLA, which is highly preferred in biomodel production due to its high resolution, increases efficiency and reproduces internal structures while producing large objects. Continuous liquid interface production (CLIP), a recently developed SLA modification, simplifies SLA by increasing the production speed. In this technique, the polymer material is condensed with light. Micromirror arrays are used to control the light intensity in these areas as it is a necessity. This technique has many advantages. For example, hydrogels are not affected by the number and complexity of the layers, the printing time is the same for each layer. Thus the SLA technique can 
significantly reduce the duration of the printing process. It is also a nozzle-free technique with high cell viability and resolution (Figure 6).

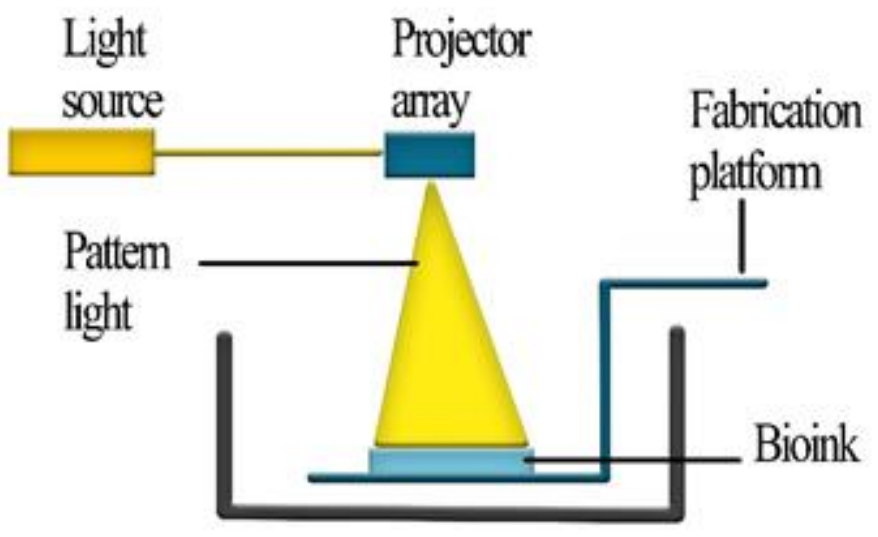

Figure 6. Schematic of stereolithography as a 3D bioprinting technique.

As a medical practice, SLA is often used for the manufacturing of anatomical models for presurgical planning. Although it has many advantages, its main disadvantage is the scarcity of hydrogels with SLA processing properties. Another disadvantage is that there are no compositional gradients along the horizontal planes (Melchels, Feijen \& Grijpma, 2010; Chae et al., 2015).

In Table 3, the properties of various bioprinting techniques are compared.

Table 3. Comparison of existing bioprinting techniques.

\begin{tabular}{ccccc}
\hline & Inkjet-based & $\begin{array}{c}\text { Extrusion- } \\
\text { based }\end{array}$ & Laser-based & Stereolithography \\
\hline Viability & $>85$ & $40-80$ & $>95$ & $>85$ \\
Speed & Fast & Slow & Medium & Fast \\
Cost & Low & Medium & High & Low \\
Vertical Structure & Poor & Good & Medium & Good \\
\hline
\end{tabular}

\section{TYPES OF BIOINKS}

Bioinks are important components of bioprinting and consists of living cells and biomaterials that mimics the extracellular matrix environment necessary for the attachment of cells. Bioinks are used to encapsulate desired cell types and to create tissue structures. Cell-loaded bioinks are based on hydrogel, which almost all of its content is water which is beneficial for cell viability and protection of the cells from production-dependent forces. To support cell proliferation and functions after printing, bioinks should have favorable rheological, mechanical, physical and chemical properties. These features can be listed as in the Figure 7. The features shown in the Figure 7 can significantly affect printing accuracy, cell viability, proliferation and morphology after printing. 


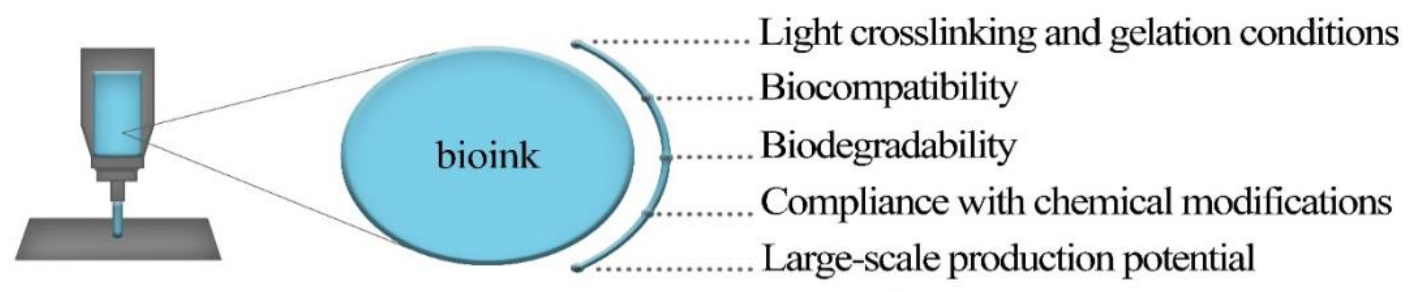

Figure 7. Bioinks should have important properties such as being biocompatible and biodegradable. They should be modifiable and crosslinkable to be able to form the 3D shape. Moreover, bionks should carry the potential to be produced in large-scales.

The bioinks are different for each bioprinter and the same bioink cannot be used in all of the bioprinter types. Bioinks are specific for every application, hence they should be suitable to modification. When selecting bioinks, it is suggested to choose the ones that can be modified in order to obtain better results according to the properties of the tissues and organs trying to be obtained. Therefore, many natural and synthetic biomaterials and mixtures of these materials have been used as bioinks.

The polymers obtained from plants and animals then used as biomaterials are called natural biomaterials. Animal-sourced bioinks enable much better cell reproduction and function compared to plant-based bioinks. These natural biomaterials have biocompatibility, biodegradation and biomimicking of ECM structure advantages over synthetic materials. In contrast with, synthetic polymers provide the feature that is not easily possible in natural biomaterials, such as controlling mechanical stability, $\mathrm{pH}$ and temperature responses. While the limited modification capacity and the difficulty of these modifications should be considered, the use of natural biomaterials as bioinks gives better results in terms of cell viability and growth than synthetic ones.

Adjustable properties are obtained in bioinks to be used for 3D bioprinters by combining natural polymers with either synthetic or another natural polymer. As mentioned earlier, although synthetic biomaterials do not have as much potential as natural biomaterials in terms of cell viability and growth, they allow to improvement of properties such as mechanical properties and crosslinking, which are important in 3D bioprinting.

In this section, the most widely used bioink materials for 3D bioprinting are discussed and also summarized in Table 4.

Table 4. Types of bioinks and comparison of their advantages and disadvantages.

\begin{tabular}{|c|l|l|l|l|}
\hline Source & Bioink & $\begin{array}{l}\text { Printing } \\
\text { Tech. }\end{array}$ & Advantages & Disadvantages \\
\hline \multirow{4}{*}{ Alginate } & $\begin{array}{l}\text { Extrusion, } \\
\text { laser-based }\end{array}$ & $\begin{array}{l}\text { Rapid gelation, low } \\
\text { cost }\end{array}$ & No cell binding areas \\
\cline { 2 - 5 } & Agarose & $\begin{array}{l}\text { Extrusion, } \\
\text { laser-based }\end{array}$ & $\begin{array}{l}\text { Nontoxic crosslinking, } \\
\text { biocompability, high } \\
\text { mechanical strength }\end{array}$ & Poor cell adhesion \\
\cline { 2 - 5 } & Collagen & $\begin{array}{l}\text { Extrusion, } \\
\text { laser-based }\end{array}$ & $\begin{array}{l}\text { Biocompatibility, } \\
\text { cell adhesion }\end{array}$ & $\begin{array}{l}\text { Low viscosity, low } \\
\text { mechanical integrity }\end{array}$ \\
\cline { 2 - 5 } & Gelatin & Extrusion & Biocompatibility & $\begin{array}{l}\text { Low viscosity, low } \\
\text { stability }\end{array}$ \\
\cline { 2 - 5 } & \multirow{2}{*}{ HA } & $\begin{array}{l}\text { Extrusion, } \\
\text { laser-based }\end{array}$ & Cell viability & $\begin{array}{l}\text { Poor mechanical } \\
\text { properties, } \\
\text { low stability }\end{array}$ \\
\cline { 2 - 5 } & & &
\end{tabular}




\begin{tabular}{|c|c|c|c|c|}
\hline & Fibrin & $\begin{array}{l}\text { Extrusion, } \\
\text { inkjet }\end{array}$ & $\begin{array}{l}\text { Cell adhesion, cell } \\
\text { viability }\end{array}$ & $\begin{array}{l}\text { Poor mechanical } \\
\text { properties }\end{array}$ \\
\hline & Cellulose & Extrusion & $\begin{array}{l}\text { Biocompability, low } \\
\text { cost, high mechanical } \\
\text { strength }\end{array}$ & - \\
\hline & Silk & $\begin{array}{l}\text { Extrusion, } \\
\text { inkjet, laser- } \\
\text { based }\end{array}$ & $\begin{array}{l}\text { High viscosity, slow } \\
\text { degration time }\end{array}$ & $\begin{array}{l}\text { Low cell viability, } \\
\text { lack of cell binding } \\
\text { sites }\end{array}$ \\
\hline & dECM & Extrusion & $\begin{array}{l}\text { Providing complex } \\
\text { structure of the natural } \\
\text { ECM }\end{array}$ & $\begin{array}{l}\text { Poor shape fidelity, } \\
\text { poor resolution, } \\
\text { rapid degradation, } \\
\text { immunogenic } \\
\text { (animal-derived) }\end{array}$ \\
\hline & Chitosan & - & $\begin{array}{l}\text { High mechanical } \\
\text { strength, } \\
\text { biodegrability }\end{array}$ & Low cell viability \\
\hline & Pluronic & Extrusion & $\begin{array}{l}\text { High resolution, good } \\
\text { shape fidelity }\end{array}$ & $\begin{array}{l}\text { Poor mechanical } \\
\text { properties }\end{array}$ \\
\hline 离 & PEG & $\begin{array}{l}\text { Extrusion, } \\
\text { laser-based }\end{array}$ & $\begin{array}{l}\text { Adjustable mechanical } \\
\text { properties, low cost }\end{array}$ & $\begin{array}{l}\text { Cytotoxicity (due to } \\
\text { UV), poor cell } \\
\text { adhesion }\end{array}$ \\
\hline
\end{tabular}

\section{Natural Biomaterial-Based Bioinks}

Biomaterials derived from natural sources are called natural biomaterials. These natural biomaterials with properties such as biocompatibility and biodegradation are often used with different versions of natural biomaterials as bioink for 3D bioprinting.

\section{Alginate-based Bioinks}

Alginate or alginic acid, is a naturally occurred polysaccharide primarily attained from the cell walls of brown algea and used for many biomedical applications due to its favorable properties (Axpe \& Oyen, 2016). One of these is that the ability of alginates to form a hydrogel polymer that stands out with its resemblance to the extracellular matrix by crosslinking through the existence of bivalent cations such as $\mathrm{Ca}+2, \mathrm{Mg}+2$. Alginates show low toxicity and are relatively low cost compared to other biomaterials. Through ease of gelation, high biocompatibility and other features, they have been adopted as bioinks (Abasalizadeh et al., 2020).

Depending on their concentration, alginates can form hydrogels in a range from low viscosity soft hydrogels to viscous hydrogels (Lee \& Mooney, 2012). They have shear thinning features which provides stress relief. Thus, during the printing process, alginates safeguard to the cells from stress. Although their use in lower concentrations is recommended because it increases cell viability, alginates are not cell adhesive. Furthermore, in 3D printing applications of alginate at lower concentration cannot achieve a good resolution. Previous researches towards improving the resolution of alginate printing suggests mixing alginate with high molecular weighted polymers. 
Alginates are generally formulated as bioinks for inkjet printing. Many examples of usage of alginates as bioinks for 3D bioprinting of different tissue engineering models were reported. While the prominent of these studies are related to alginate based hydrogels produced with different combinations, stem cell bioprinting by using alginate bioinks are also frequently included in these studies. For 3D bioprinting of engineered scaffold bone tissue, an alginate based hydrogel developed by combining with polyvinyl alcohol-hydroxyapatite were reported in 2017 (Bendtsen, Quinnell, \& Wei, 2017). In another study, a technique has been reported, using alginate/gelatin methacryloyl (GelMA) bioink, which allows direct bioprinting of endothelial cells into microfibrous hydrogel scaffolds to form an endothelialized human myocardium (Zhang et al., 2016). In the studies for stem cell bioprinting, there is a study in 2017 , whose detailed explaination can be found in the fourth section of this article, where alginate was used as bioink with nanofibrillated cellulose (NFC) for 3D bioprinting of induced pluripotent stem cells (iPSCs) to support cartilage manufacture (Nguyen et al., 2017). In 2015, alginate based bioink was used in the 3D bioprinting of human pluripotent stem cells (hPSCs) to produce a three-dimensional mini liver. AlginateRGD (Arg-Gly-Asp) bioink was created for this study (Faulkner-Jones et al., 2015).

These studies reveal that alginate based bioink can be used for multiple purposes and because of its numerous advantages, it is mostly preferred as bioink materials in $3 \mathrm{D}$ bioprinting.

\section{Agarose-based Bioinks}

Agarose, a polysaccharide derived by extracting from seaweed, is used as a biopolymer for different purposes in the biomedical field. It has been used as a bioink because of its gel formation at low temperatures with non-toxic crosslinking and high stability, biocompatibility, and mechanical strength. Due to the non-crosslinker gelling feature of agarose, printing of complex structures is possible. However, poor cell adhesion ability to support cell growth appears as a problem. To overcome of this, various efforts have been conducted by combining agarose with other biomaterials to improve the cell adhesion properties of the agarose gel. In a study, the ability of agarose to support endothelial and fibroblast cell growth was shown when blended with collagen and fibrinogen (Kreimendahl et al., 2017). Agarose-based hydrogels are commonly used for 3D bioprinting of cartilage tissue since the requirement for cell sprouting is minimal in this case. An example for these applications, the use of collagen and sodium alginate blend with an agarose-based bioink has been reported. It was shown that mechanical properties of the material was improved while not effecting the gelation properties (Yang et al., 2018). Among the different hydrogels tested as bioinks for cartilage in tissue engineering, the agarose-alginate mixture showed the highest potential (Daly, Critchley, Rencsok, \& Kelly, 2016a). The most advanced hyaline-like cartilage result has been reported to be obtained in trials using alginate and agarose hydrogels as bioinks (Daly et al., 2016a; Roberts \& Martens, 2016). Since good gelation property alone is not sufficient for using of agarose as bioink, chemical modifications or blending are required to develop the above-mentioned deficient properties.

\section{Collagen-based Bioinks}

Collagen is a natural polymer found in almost all biological tissues especially in the connective tissues of skins and bones and is derived from natural extracellular matrix. Due to its high biocompatibility, collagen has been adopted as a natural bioink material in 3D bioprinting and has been used for many years. Collagen can be preferred either alone or in combination in 3D bioprinting usages. It should be noted that its low viscosity makes pure collagen hydrogel difficult for bioprinting. In order to overcome this problem, modifying the collagen by blending with other materials is the most preferred method. The characteristics of collagen are affected by molecular structure, molecular weight, and temperature. These effects can change the viscosity and formation of the collagen hydrogel. Despite almost 30 types of collagen protein present in human cells, due to its abundance, type I collagen is frequently preferred and used for tissue 
engineering applications. Collagen molecules consisting of three polypeptide chains, forms a triple helix structure by extending these chains which contains cell adhesion sites based on the transmembrane receptor binding motifs of arginine-glycine-aspartic (RGD) residues (J. E. Kim, S. H. Kim, \& Jung, 2016). Cell adherence sites on the chains provide a higher potential to support cell growth to collagen-based bioinks. Also during printing, collagen protects the cells. Collagen has the ability to crosslink using temperature or $\mathrm{pH}$ change. The crosslinks formed allow the structure to increase its mechanical properties. Thus, the tensile strength and viscoelastic properties of crosslinked collagen increases compared to non-crosslinked collagen. Crosslinking or gelation of collagen takes longer than other biomaterials, however improved mechanical properties are more preferred for 3D bioprinting.

Studies using collagen as bioink in extrusion, inkjet, droplet-based, electromechanical jetting and laser-based printing have been reported. In a study dated 2018, corneal structures resembling the natural human corneal stroma structure were 3D bioprinted with collagen-based bioinks containing encapsulated corneal keratocytes (Isaacson, Swioklo, \& Connon, 2018). In another study, collagen hydrogel bioinks were preferred to create the vascularized mouse thyroid gland structure (Bulanova et al., 2017). Collagen I has been studied as bioinks with keratinocytes and fibroblast cells for the forming of human skin by 3D bioprinting (Lee et al., 2014).

\section{Gelatin-based Bioinks}

Gelatin is a biopolymer that derives from the hydrolysis of collagen, and because it is derived from collagen, it has the potential to have almost the same properties as collagen. The biocompatible structure of collagen, as cited before, is also seen in gelatin which is its hydrolyzed form. Since gelatin is obtained naturally from sources at sea, it does not have the risk of carrying disease as those obtained from other sources. The fact that the structure of gelatin has properties that support cell growth and that it easily forms hydrogels with physical crosslinks at low temperatures such as room temperature causes it to be used as a biomaterial in 3D bioprinting applications. Unfortunately, besides this advantage of ease thermal gelation, whereas gelatin has a very low melting point, which is lower than the human body temperature, that comes with a conclusion as restricting its vivo administration. Fortunately, it offers a structure in which these features can be easily adjusted for 3D bioprinting. In order to improve poor bioprinting solubility, shape fidelity and to achieve better results, blending of gelatin with other polymers has also been a preferred method for increasing the low viscosity of their hydrogels (Ahangar, Cooke, Weber, \& Rosenzweig, 2019). Mixing gelatin methacrylamide (GELMA) with gellan gum, one of the studies in which gelatin is blended with different viscous polymers to increase the viscosity, has the most popular research results (Panwar \& Tan, 2016). This mixture hydrogel structure which offers adjustable physical properties to researchers, is used and developed in many biomedical applications other than 3D bioprinting. The GELMA structure crosslinking takes place chemically. Since this process requires exposure to UV light, care must be taken to avoid potential DNA damage due to UV radiation. These easily adjustable properties of GELMA hydrogel mentioned before enable the usage of it in extrusion, inkjet and SLA-based bioprinting.

\section{Hyaluronic Acid-based Bioinks}

Hyaluronic acid (HA), a component of the extracellular matrix, is a glycosaminoglycan composed of repeating disaccharide units. Already taking part in regulatory tasks such as cell growth, migration and differentiation within the cell makes it indispensable for biomedical applications especially in tissue engineering and regenerative medicine. HA protects the cells from pressure stress during printing and offers an environment to improve cell vitality and function by its nature. Hydrogels of HA have high viscosity, which is one of the generally preferred properties in three dimensional bioprinting. However, the rareness of crosslinking in these gels weakens the mechanical strength properties of the HA hydrogel. Therefore, methods such as thiolation and methacrylation to increase the degree of cross-linking have been used in 
researchs to modify HA hydrogels. Studies that have successfully crosslinked hyaluronic acid hydrogels physically and photochemically have been reported (Noh et al., 2019). Methacrylated HA (HA-MA), a modified form of HA, has been observed to form stable crosslinks along with the photoinitiator in the media when exposed to UV light (Merceron \& Murphy, 2015). These methods were used to improve shape fidelity and good results have been obtained. HA, which has a biocompatibility profile, can also be made more resistant to degradation by enzymes thanks to the cross-links in its hydrogels. They are preferred as bioink in extrusion printing and stereolithographic printing applications.

\section{Fibrin-based Bioinks}

Fibrin, a protein formed as a result of the enzymatic reaction of thrombin and fibrinogen in the blood, has taken its place in 3D bioprinting applications as bioinks thanks to its biocompatibility and biodegradability of hydrogels formed by these proteins, like many other hydrogels. However, studies for the use of fibrin for 3D bioprinting are fewer than those in other areas of tissue engineering applications. Due to the low viscosity of the hydrogels of fibrin, they are useful in inkjet bioprinting methods, and they are also used as an additive in extrusion bioprinting by increasing its mechanical strength with other biopolymers (Wang, 2019). The properties of this structure, which provides cell adhesion, support and viability, can be adjusted for its components using different proportions. Although the rapid crosslinking time of this biocompatible biomaterial is an advantage, its irreversible and rapid gelling at human body temperature and rapid degradation time limits its use in the bioprinting field (Merceron \& Murphy, 2015). Studies have been developed in which it is blended with different polymers to develop poor mechanical properties. These include attempts to improve stability.

\section{Cellulose-based Bioinks}

Cellulose, which is the main ingredient of plant cell walls gives the plant a hard and strong structure. Cellulose is a natural polysaccharide used as itself or its derivatives as bioinks to provide structural and mechanical support to printed structures in 3D bioprinting. The method of blending cellulose with bioactive polymers is frequently used to improve the three-dimensional structure of the cells, increase the viability of the cells and enhance the mechanical properties of biomaterial printed via 3D bioprinter (Gopinathan \& Noh, 2018). Examples to known derivatives of cellulose, nanofibrile cellulose (NFC), which is used as a shear-thinning agent in other bioinks, and methyl-cellulose (MC), which can form hydrogel reacts against external stimuli by easily changing its properties such as concentration or molecular weight, can be given.

\section{Silk-based Bioinks}

Silk which is protein rarely used alone in regenerative medicine and tissue engineering but mostly blended with other polymers is obtained by harvesting from silkworms and spiders (Gopinathan \& Noh, 2018; Derakhshanfar et al., 2018). The versions of silk and itself are preferred as bioinks since they contain all of the properties that should be in an ideal biomaterial to develop a bioink such as high viscosity, slow condition of degrading, shear thinning and not causing an immune response. In addition, silk provides a protection to the cells against stress that occurs during bioprinting. However, high viscosity silk hydrogels, considered as an advantage for bioprinting, can clog the nozzle during printing. Although all of these mentioned possibilities exist in one material seems great, silk does not have cell binding sites that allow cell adhesion, which adversely affects cell growth and functionality. In order to improve these and the shape fidelity of the 3D bioprinted biomaterials, studies are made in which silk is blended with other polymers. 


\section{Decellularized Extracellular Matrix (dECM)-based Bioinks}

dECM is a natural polymer mixture produced by the decellularization of animal tissues using chemical, physical or combining these methods, while ensuring the ECM remains the same without changing its properties which provides the necessary physical scaffold for cellular components. Using the ECM itself is important for tissue engineering and regenerative medicine applications, as the complex structure of the natural ECM to meet the cell needs by a single material cannot be fully represented when creating bioinks (Turunen et al., 2018). Bioinks are created using the powder form of dECM in a buffer solution (Gopinathan \& Noh, 2018). Derivation of dECM from different tissues causes it to have a wide range in terms of cell growth and differentiation factors. However, because dECM is derived from animal tissues, it is likely to contain immunogens that can cause immune responses in host tissues (Dzobo, Motaung, \& Adesida, 2019). Since dECM has generally low viscosity, it exhibits weak mechanical properties. Its shape fidelity and bioprinting resolution is poor and its biodegradation occurs very rapidly. Various studies have been carried out to overcome these problems, including physical and chemical crosslinking and blending of dECM with other polymers.

\section{Chitosan-based Bioinks}

Chitosan, which is used in medical applications, is derived from the chitin which is a biodegradable fiber developed from the shells of shellfish. A study has been reported that successful results were obtained where the hydrogel of chitosan which has high mechanical strength, antimicrobial property, bioactivity and biodegradability was used as bioink in 3D bioprinting for bone tissue engineering (Demirtaş, Irmak, \& Gümüşderelioğlu, 2017; Zhang et al., 2019). Chitosan amino groups can be easily changed for different purposes in 3D bioprinting, and derivatives with suitable properties for applications can be obtained.

\section{Synthetic Polymer-based Bioinks}

Synthetic polymers are unique polymers that are artificially produced by chemical reactions of repeated structural units known as monomers. These polymers provide advantages over the natural biomaterial bioinks such as adjusting mechanical properties and degradation rate, which are important in bioprinting, as desired and functionalizing of them with a wide range of biofactors. However, since melting points of most biodegradable varieties reach up to $200^{\circ} \mathrm{C}$ which is almost quintuple of the human body temperature, and since synthetic ones cannot provide a suitable medium to support cell adhesion and viability compared to the natural biomaterial bioinks, synthetic polymers take place only in $10 \%$ of the bioinks used in three-dimensional bioprinting. Synthetic polymers that are being used as bioinks includes pluronic acid, polyethylene glycol (PEG), polyurethane (PU), poly(lactic-glycolic acid) (PLGA), poly( $\varepsilon$ caprolactone) (PCL), and poly(L-lactic acid) (PLLA) (Merceron \& Murphy, 2015; Wang, 2019; Gopinathan \& Noh, 2018).

\section{Pluronic Acid-based Bioinks}

Pluronics or poloxamers are nonimmunogenic synthetic tri-block copolymers composed by the sequences of poly (ethylene oxide), poly (propylene oxide), poly (ethylene oxide), shortly PEO-PPO-PEO structure are often used in tissue engineering. The hydrophilic property of ethylene oxide and the hydrophobic property of propylene oxide provide amphiphilic properties to the structure of pluronics that allow them to form self-assemble micelles in aqueous solutions. Since micelle formation affects the degradation properties of the biomaterial, it is taken into consideration when choosing bioinks for threedimensional bioprinters. Most prominent feature of pluronic using as a bioink is its rapid and self-assembly gelation process at room temperature. Other properties can be continued as forming of viscous gels and 
providing high resolution and good shape fidelity to the printed tissues or organs. Providing good resolution is a major factor in the use of pluronic as bioink in three-dimensional printing of vascular network, and viscous structure of their gels enables easy fabrication of complex 3D stuctures. Besides their advantages, the synthetic structures of these polymers create disadvantages such as low cell binding affinity and lack of ability for degradation. And also weak mechanical properties of pluronic are weak, thus, the good shape fidelity of the pluronic immediately after printing is not long-lasting. In a study, it has been reported that pluronic bioink lacks the ability to protect cells from stress during bioprinting (Panwar \& Tan, 2016). Even though pluronic has these mentioned disadvantages, it is mostly used as sacrificial molding agent in 3D bioprinting.

Although the studies used of pluronic as bioink for different bioprinting methods other than extrusion-based bioprinting are almost nonexistent, a study has been reported where the mixture of pluronic with another hydrogel has been tried as a bioink for the inkjet bioprinting (Merceron \& Murphy, 2015).

\section{PEG-based Bioinks}

This synthetic polymer, which comes up with different names according to its molecular weight, is simply known as polyethylene glycol (PEG). The differentiation in its molecular weights is achieved by ring-opening polymerization of ethylene oxide, and these polymerization levels give it the names PEG, poly (ethylene oxide) (PEO), and poly (oxyethylene) (POE). Having a so easily changeable molecular weight allows its rheological and mechanical properties to be tunable, making PEG an inevitable opportunity to use it as bioinks in 3D bioprinting applications. Also it offers different geometry configurations that can be synthesized from linear to multi-arm PEGs. So far this versatile structure allows it to be used for various purposes in many different fields such as medicine, biology, industry and commercial. Its biocompatibility, nonimmunogenic, hydrophilic structure, low cost and FDA approval make PEG and its varieties an excellent bioink candidate. So much so that PEGs are one of the most preferred bioink type among synthetic biomaterial based bioinks.

Since PEGs cannot form hydrogels alone, they require chemical modification to create a cross-linked three-dimensional structure. The two hydroxyl groups in its structure are converted into functional groups such as acrylate, methyloxyl, thiol, amine, carboxyl and acetylene through physical or covalent crosslinking, thus PEG can be easily adapted to the desired mechanical properties in three-dimensional bioprinting studies. PEG-diacrylate (PEGDA) and PEG-dimethylacrylate (PEGDMA) forms of PEG formed as a result of acrylation and methacrylation are the main types of PEG used when forming bioinks (Merceron \& Murphy, 2015; Ashammakhi et al. 2019). Cross-links can occur in PEG forms using photoinitiation. Customizable mechanical properties of PEG makes it more advantageous than other synthetic polymers for printing multilayered structures. Furthermore, the hydrophilic structure of PEG allows cell encapsulation. Although its many advantages, and resistance of its hydrogels to protein adsorption, which allows to create desired biofunctionality, the lack of cell binding sites adversely affects cell adhesion, limiting the use of PEG-based bioinks in 3D bioprinting applications. RGD peptide modification applications have been developed and used to increase cell adhesion ability in PEGs for bioprinting.

While low viscosity prevents the use of PEG-based hydrogels in extrusion bioprinting applications, it offers the advantage of preserving shape fidelity in other bioprinting applications such as inkjet bioprinting. PEG-based hydrogels are mixed with other biomaterials for using in extrusion biopressure, and improving their properties accordingly. PEG can be used as a crosslinker to improve the bioprinting resolution of other bioinks.

\section{Nanocomposite Bioinks}

By combining polymers with nanofillers such as carbon nanotubes, silicates, ceramics and metals, nanocomposite bioinks are formed for creating a variety in three-dimensional bioprinting applications by 
enhancing mechanical or chemical structural properties of these polymers. Although nanocomposite bioink studies have been developed and used for tissue engineering already, the potential of nanocomposite bioinks is not clear in three-dimensional bioprinting. However there is really powerful belief that nanocomposite bioinks can impart unique properties to 3D bioprinted structures.

\section{BIOPRINTING FOR TISSUE ENGINEERING AND REGENERATIVE MEDICINE}

Studies are rapidly propagating to the ultimate goal of producing functional living organs for transplantation using bioprinting. Some the findings on the use of bioinks for bioprinting are discussed below.

Bioprinting of keratinocyte cells by producing bioinks suitable for three-dimensional bioprinters were made. Tests, such as cell proliferation, viability analysis and cell distribution were performed and morphology of the epidermis tissue culture with hydrogel structure was determined for the obtained structure. The hydrogel most suitable for bio printing was determined using three different hydrogels like gelatin, alginate and chitosan. As a result of the researches, it was determined that got tissues were effectively produced using 3D bioprinting, and keratinocytes were able to join the hydrogels and retain their viability. The produced bioinks can be used as a treatment for skin injuries such as burns. (Ürkmez, Seçkin, Görgün, \&Uyanıkgil, 2018)

The use of bioinks is a promising development in the field of regenarative medicine. Nevertheless, full success cannot be achieved as bioinks cannot meet the intrication of the natural extracellular matrix (ECM). To solve this problem, a research was made to whether bioinks can be made while preserving the natural extracellular matrix. In the first place, tissue printing was performed with a specific decellularized extracellular matrix biopsy covering live hASCs or hTMSCs. As an outcome of this research, the usage of bioinks prepared with cell-free (dECM) tissues for in vivo and in vitro tissue functions has been opened. (Pati et al., 2014)

The structure of bioinks has an important role in cell printing. If the crosslinks are installed incorrectly in bioinks, shaping will not be as desired while printing. For this reason, dECM bioinks with heat modules that allow cross-linking at the same time have been designed. As a result of the tests, it has been observed that it has more printability than bioinks without a heat module. At the same time, no cell death due to the heat module was found. In addition, it was determined that the viscoelasticity increased at higher bioink concentrations, hence, the collapse was less and it could support itself more easily. (Ahn et al., 2017)

Whether iPSCs are proper for bioprinting to assist cartilage production have been investigated. To facilitate the adaptation of iPSCs to their phenotypic properties, nanofibrilized cellulose composite has been used, which provides structural and mechanical support to create the physiological mimicry environment. Alginate and hyaluronic acid have also been used to assist cells. As a result of the research, together with these hydrogel combinations, iPSCs have been observed to be suitable for cartilage formation in 3D bioprinting. (Nguyen et al., 2017)

Despite three-dimensional bioprinting technology has drew great attention in the field of regenerative medicine, there are some engineering difficulties to overcome. For long-term shape stability, bioinks need to meet basic criteria such as printable, biocompatible and structural and mechanical stability. Especially when using DLP modality, the dynamics of the polymerization, changing the power of the light source, the printing speed, the type and concentrations of the photoinitiators should be adjusted. Silk fibroinbased bioinks were made. With this Sil-MA hydrogel, it was observed that complex structures can be printed in one press, higher print lengths can be achieved compared to other hydrogels, cell distribution and net printing can be achieved as designed even if the print size is small. Flexible and stretchable structures were obtained as the Sil-MA concentration increased. Based on the mechanical properties obtained as a result of the research, Sil-MA can be used for many clinical applications. (Kim et al., 2018) 
Finding bioinks that meet physical, chemical and biological requirements and developing biomaterial ink (BmI) is the biggest challenge in biofabrication. In order for the tissues to be successful, BmIs and bioinks must act like natural cells. Bioinks hardness and porosity should be like to the natural extracellular matrix to assist cell growth and proliferation. As mentioned earlier, most of the materials developed cannot meet these requirements. The nucleotide lipid-based hydrogel forms soft scaffolds that can mimic the extracellular matrix have been observed. This hydrogel can be used as biomaterial ink or bioinks. (Dessane et al., 2020)

It is a very important issue to heal muscle defect injuries caused by the loss of the structural and functional properties of the natural skeletal muscle. Treatment of muscle injuries has clinical difficulties. Therefore, restoring the normal function of the skeletal muscle will be an important improvement in extensive muscle defect injuries. The effect of neural cell integration on muscle regeneration has been investigated. Human muscle progenitor cells (hMPC) and human neural stem cells (hNSC) were used to resolve problems caused by innervation. Neuromuscular junction (NMJ) formation was observed with the combined use of these cells. It was also observed that the innervation was facilitated and the functionality was recovered in some muscle defect injuries. (Kim et al., 2020)

Bioinks take an important place to improve the functions of 3D printed tissues. An ideal bioink should be printable, non-toxic, biocompatible and able to mimic the natural extracellular matrix. The properties of bioinks can be affected by various parameters. The impact of ionic strength of the solvent on alginate gelatin bioinks has been analyzed. As the ionic strength of the solvent used in bioinks increased, a lower viscosity was observed. It was also found that the solvent had low ionic strength, less swelling and degradation. In line with the research, it was understood that the ionic strength of the solvent had a significant effect on the printability, mechanical properties and characteristics of the cell of bioinks. (Li et al., 2018)

\section{FUTURE PROSPECTS}

Bioprinters are promising and emerging technologies for creating 3D tissue units of different structures and geometries using many living tissues and biomaterials (Güngör-Özkerim et al., 2018). These devices enable the production of specific scaffolding and tissue models with high complexity about structure and numerous design types for patients. It has the potential to be widely used in medicine due to its many advantages such as this one (Ji \& Guvendiren, 2017). This usable potential has enabled the production and transplantation of various structures such as bone, heart tissue, cartilaginous tissues and many more (Hölzl et al., 2016). One of the main components of bioprinting is bioinks and they consist of various cells and biomaterials (Güngör-Özkerim et al., 2018). Cell-wool hydrogels are the most common bio-inks that offer new strategies (Ji \& Guvendiren, 2017). In addition, ECM-based bioinks, cell-free bioinks, cell aggregates or spheres, bioinks used in 3D biological printing technology have promising results for the development of tissues and organs (Gopinathan \& Noh, 2018). Although dECM-based bioinks provide an alternative approach, transaction of tissue which is decellularized enhances the cost of ink making (Ji \& Guvendiren, 2017). The presence of bioink in many features and types, the availability of appropriate modeling tools and the ability to use these materials in different geometries reveal the advantages of biological printing. The bioink and bioprinting required for different applications have come a long way in a short time. Therefore, the materials planned to be used for biological printing have been systematically researched and adjusted to suit different technologies (Hölzl et al., 2016). Although biological printing is an area open to development, the production of bioinks that can fully meet the requirements sought has been restricted due to various biological, mechanical and similar reasons. Many studies are needed to develop bioink structures and to establish new standards (Güngör-Özkerim et al., 2018). In addition to the development of bioinks, it is thought that bioprinters have higher resolution and lower costs, which can increase the expectations of research areas (Gopinathan \& Noh, 2018). Current manufacturing procedures are currently not sufficient to produce all organs because of complex nature, but 
simple structures or tissues can be produced (Hacioglu, Y1lmazer \& Ustundag, 2018). Moving of 3D bioprinted structures to the clinic still needs more arrangements (Ji \& Guvendiren, 2017).

The future of bioink and 3D bioprinting is promising because new biomaterials containing supramolecular functionality, recycled crosslinking polymers and stimuli-sensitive hydrogels will greatly contribute to the development of this area. Such developments lead to the development of improved tissues and devices specific to the patients (Gopinathan \& Noh, 2018). In some of the studies on bioprinters, models that allow evaluating the mechanic features of hydrogels which contains various cell distributions and densities are presented. These models can be expanded over time to include more complex 3D structure architectures and can be used for determining the estimated cellular loading, mechanical response and longitudinal behavior of cells which are printed in various hydrogel structures. Such studies can be squarely associated with organ development and tissue modeling (Hölzl et al., 2016). Two of the most interesting candidates for bioink design are supramolecular hydrogels with cross-linking mechanisms and stimulating materials for biomimetic 4D printing (Ji \& Guvendiren, 2017).

Improving biological printing practices depends on many substances. Some of these are stem cell technology, material science technology, and production capabilities of bioink components. Moreover, principles such as post-pressure treatments, self-assembly and self-regulation can be considered as solutions to produce complex organs. When these problems are solved, biological pressure will be one of the most important inventions in the world (Hacioglu, Y1lmazer \& Ustundag, 2018). Controlled and stimuliresponsive release of growth factors and immunomodulators will enable the ability to control the bioactivity of bioinks. Steps taken in the fields of nanomaterials, chemistry of polymer, material for 3D biological printing and technics of stem cell will make easier the improve of bioinks which are hydrogel (Chimene, Lennox, Kaunas \& Gaharwar, 2016).

Some problems related with functionality, printability and safety of the material in biological printing methods are an issue to be investigated for therapeutic and non-therapeutic applications (Liu J et al., 2018). Bioprints with multiple printheads are the technologies required to generate heterogeneous and complex tissue structures quickly. These devices can accumulate versatile formulations concurrently to produce complex tissue structures which involves vascularized tissues. In recent studies, the use of multiple polymeric inks has been investigated. Mechanical development of multicomponent polymeric bioinks including shear thinning nanoparticles can be achieved. Adding microparticles and nanoparticles containing growth factor to the ink medium in the polymeric network will supply adjunct tools to check the cell destiny. One of the most important reasons for the complex tissue structures that are intended to be produced by operating 3D bioprinting is the restricted existence of multiple bioink. As a solution to this problem, multimaterial bio-inks have been one of the most researched areas, but many promising combinations of polymers have not been evaluated yet (Chimene et al., 2016). The use of naturally derived biopolymers as bioinks in biomedical and pharmaceutical executions is noted one of the most up and coming fields in the extension of 3D biological printing because these materials which have high abudance, low cost, biocompatibility and biodegradability. Apart from these features, difficulties such as mechanical properties, supplies imperfections, biocompatibility, tissue biomimicry and degradation kinetics in 3D printing which biopolymers have, used in medical fields are important requirements. The natural physiochemical properties of some biopolymers require innovations such as a change of printers which are commercial, change of natural biopolymers, advancing new solvent systems, and involving another bioactive. In future research, efforts can be made to enlarge the restricted diversity of naturally gained biopolymers. Some of these include the improvement of new solvent systems that are cell-friendly and can dissolve or disperse naturally derived biopolymers as ink formulations, the management of several biopolymers and the inclusion of different biomolecules like compound inks with properties such as the desired workability, printability, mechanics, bioactivity, biodegradability and chemical. The inclusion of components sensitive to physical stimuli in naturally derived biopolymers. When these challenges are overcomed, it can be estimated that there will be the use of naturally derived 'green' raw materials as future material for 3D bioprinting 
technology. Such raw materials that can be used to make the potentially available 3D printing programmable and turn it into a future 4D print (Liu J et al., 2018).

\section{CONCLUSION}

3D biological printing is a hopeful process for the area of tissue engineering, including the creation of most complex structural architectures, vascularization of tissue structures and the orientation of stem cell differentiation. There are many types of bioprints that can be preferred in certain control and various designs, but several difficulties remain to create some complicated tissues, comprising several cell types. Most especially, bioink materials needs to be developed to clinically apply bioprine technology. Bioink formulation can be considered as one of the most important elements for the bioprinting process. A proper bioink must perform several rheological, mechanical and biological necessities during and after printing. Generally, according to the desired feature, they are branching under two main headings as natural-based and synthetic. Throughout this article, bioprinting methods and bioinks which have many different properties and are used for various purposes are indicated. At the same time, studies on tissue engineering and regenerative medicine and many promising possibilities for bioink are mentioned. Each method has its advantages and disadvantages according to its intended use. New techniques are being developed in order to eliminate these drawbacks.

Despite all the difficulties, 3D bioprinting has progressed towards its goal to enable functional tissue printing since its discovery, and this method has clearly proved fitting of ongoing research. Further time, working and multidisciplinary speciality will be required to perform the clinical potential of this technology, but the future is bright. Biological printing is ready to play an important role in personalized regenerative medicine.

\section{ACKNOWLEDGEMENTS}

The authors would like to thank Selcan Ünal for the support provided for the Figures.

\section{REFERENCES}

1. Güngör-Özkerim, P.S., İnci, I., Zhang, Y.S., Khademhosseini, A. \& Dökmeci, M.R. (2018). Bioinks for 3D bioprinting: an overview. Biomaterials science, 6(5), 915-946. https://doi.org/10.1039/c7bm00765e

2. Hölzl, K., Lin, S., Tytgat, L., Van Vlierberghe, S., Gu, L., \& Ovsianikov, A. (2016). Bioink properties before, during and after 3D bioprinting. Biofabrication, 8(3). https://doi.org/10.1088/17585090/8/3/032002

3. Kačarević, Ž.P., Rider, P.M., Alkildani, S., Retnasingh, S., Smeets, R., Jung, O.,... Barbeck, M. (2018). An Introduction to 3D Bioprinting: Possibilities, Challenges and Future Aspects. Materials (Basel, Switzerland), 11(11). https://doi.org/10.3390/ma11112199
4. Melchels, F.P., Feijen, J., \& Grijpma, D.W. (2010). A review on stereolithography and its applications in biomedical engineering. Biomaterials, 31(24), 6121-6130. https://doi.org/10.1016/j.biomaterials.2010.04.050

5. Chae, M.P., Rozen, W.M., McMenamin, P.G., Findlay, M.W., Spychal, R.T., \& Hunter-Smith, D.J. (2015). Emerging Applications of Bedside 3D Printing in Plastic Surgery. Frontiers in surgery, 2, 25. https://doi.org/10.3389/fsurg

6. Axpe, E., \& Oyen, M. L. (2016). Applications of Alginate-Based Bioinks in 3D Bioprinting. International journal of molecular sciences, 17(12), 1976. https://doi.org/10.3390/ijms17121976

7. Abasalizadeh, F., Moghaddam, S. V., Alizadeh, E., Akbari, E., Kashani, E., Fazljou, S., Torbati, M., 
. . Akbarzadeh, A. (2020). Alginate-based hydrogels as drug delivery vehicles in cancer treatment and their applications in wound dressing and 3D bioprinting. Journal of biological engineering, 14, 8. https://doi.org/10.1186/s13036020-0227-7

8. Lee, K. Y., \& Mooney, D. J. (2012). Alginate: properties and biomedical applications. Progress in polymer science, 37(1), 106-126. https://doi.org/10.1016/j.progpolymsci.2011.06.00 3

9. Bendtsen, S. T., Quinnell, S. P., \& Wei, M. (2017). Development of a novel alginate-polyvinyl alcohol-hydroxyapatite hydrogel for 3D bioprinting bone tissue engineered scaffolds. Journal of biomedical materials research. Part A, 105(5), 1457-1468. https://doi.org/10.1002/jbm.a.36036

10. Zhang, Y. S., Arneri, A., Bersini, S., Shin, S. R., Zhu, K., Goli-Malekabadi, Z., . . . \& Khademhosseini, A. (2016). Bioprinting 3D microfibrous scaffolds for engineering endothelialized myocardium and heart-on-a-chip. Biomaterials, 110, 45-59. https://doi.org/10.1016/j.biomaterials.2016.09.003

11. Nguyen, D., Hägg, D. A., Forsman, A., Ekholm, J., Nimkingratana, P., Brantsing, C., . . . \& Simonsson, S. (2017). Cartilage Tissue Engineering by the 3D Bioprinting of iPS Cells in a Nanocellulose/Alginate Bioink. Scientific Reports, 7(1), 658. https://doi.org/10.1038/s41598-01700690-y

12. Faulkner-Jones, A., Fyfe, C., Cornelissen, D. J., Gardner, J., King, J., \& Courtney, A. (2015). Bioprinting of human pluripotent stem cells and their directed differentiation into hepatocyte-like cells for the generation of mini-livers in 3D. Biofabrication, $\quad 7(4), \quad 044102$. https://doi.org/10.1088/1758-5090/7/4/044102

13. Kreimendahl, F., Köpf, M., Thiebes, A. L., Duarte Campos, D. L., Blaeser, A., Schmitz-Rode, T., . . . \& Fischer, H. (2017). 3D-Printing and Angiogenesis: Tailored Agarose-Type I Collagen Blends Comprise 3D Printability and Angiogenesis
Potential for Tissue Engineered Substitutes. Tissue Engineering Part C, Methods, 23(10). https://doi.org/10.1089/ten.tec.2017.0234

14. Yang, X., Lu, Z., Wu, H., Li, W., Zheng, L., \& Zhao, J. (2018). Collagen-alginate as bioink for three-dimensional (3D) cell printing based cartilage tissue engineering. Materials science \& engineering. C, Materials for biological applications, 83, 195-201. https://doi.org/10.1016/j.msec.2017.09.002

15. Daly, A. C., Critchley, S. E., Rencsok, E. M., \& Kelly, D. J. (2016a). A comparison of different bioinks for 3D bioprinting of fibrocartilage and hyaline cartilage. Biofabrication, 8(4), 1-10. https://doi.org/10.1088/1758-5090/8/4/045002

16. Roberts, J.J., \& Martens, P. J. (2016). Engineering biosynthetic cell encapsulation systems. In L. Poole-Warren, P. Martens, \& R. Green (Eds.), Biosynthetic Polymers for Medical Applications (Woodhead Publishing Series in Biomaterials) (pp. 205-239). Woodhead Publishing.

17. Kim, J. E., Kim, S. H., \& Jung, Y. (2016). Current status of three-dimensional printing inks for soft tissue regeneration. Tissue Engineering and Regenerative Medicine, 13, 636-646. https://doi.org/10.1007/s13770-016-0125-8

18. Isaacson, A., Swioklo, S., \& Connon, C. J. (2018). 3D bioprinting of a corneal stroma equivalent. Experimental Eye Research, 173, 188193. https://doi.org/10.1016/j.exer.2018.05.010

19. Bulanova, E. A., Koudan, E. V., Degosserie, J., Heymans, C., Pereira, F. D., Parfenov, V. A., . . \& \& Mironov, V. A. (2017). Bioprinting of a functional vascularized mouse thyroid gland construct. Biofabrication, 9(3). https://doi.org/10.1088/17585090/aa7fdd

20. Lee, V., Singh, G., Trasatti, J. P., Bjornsson, C., Xu, X., Tran, T. N., \& Karande, P. (2014). Design and fabrication of human skin by three-dimensional bioprinting. Tissue engineering. Part C, Methods, 
$20(6)$, https://doi.org/10.1089/ten.TEC.2013.0335

21. Ahangar, P., Cooke, M. E., Weber, M. H., \& Rosenzweig, D. H. (2019). Current Biomedical Applications of 3D Printing and Additive Manufacturing. Applied Sciences, 9(8). https://doi.org/10.3390/app9081713

22. Panwar, A., \& Tan, L. P. (2016). Current Status of Bioinks for Micro-Extrusion-Based 3D Bioprinting. Molecules (Basel, Switzerland), 21(6), 685. https://doi.org/10.3390/molecules21060685

23. Noh, I., Kim, N., Tran, H. N., Lee, J., \& Lee, C. (2019). 3D printable hyaluronic acid-based hydrogel for its potential application as a bioink in tissue engineering. Biomaterials Research, 23, 3. https://doi.org/10.1186/s40824-018-0152-8

24. Merceron, T., \& Murphy, S. (2015). Hydrogels for 3D Bioprinting Applications. In: A. Atala, J. J. Yoo (Eds.), Essentials of 3D Biofabrication and Translation (pp. 249-270). USA: Academic Press an imprint of Elsevier

25. Wang, X. (2019). Advanced Polymers for Three-Dimensional (3D) Organ Bioprinting. Micromachines, $\quad 10(12), \quad 814$. https://doi.org/10.3390/mi10120814

26. Gopinathan, J., Noh, I. (2018). Recent trends in bioinks for 3D printing. Biomaterials Research, 22, 11. https://doi.org/10.1186/s40824-018-0122-1

27. Derakhshanfar, S., Mbeleck, R., Xu, K., Zhang, X., Zhong, W., \& Xing, M. (2018). 3D bioprinting for biomedical devices and tissue engineering: A review of recent trends and advances. Bioactive materials, 3(2), 144-156. https://doi.org/10.1016/j.bioactmat.2017.11.008

28. Turunen, S., Kaisto, S., Skovorodkin, I., Mironov, V., Kalpio, T., \& Vainio, S. (2018). 3D bioprinting of the kidney-hype or hope? AIMS Cell and Tissue Engineering, 2(3), 119-162. https://doi.org/10.3934/celltissue.2018.3.119
29. Dzobo, K., Motaung, K., \& Adesida, A. (2019). Recent Trends in Decellularized Extracellular Matrix Bioinks for 3D Printing: An Updated Review. International journal of molecular sciences, 20(18). https://doi.org/10.3390/ijms20184628

30. Demirtaş, T. T., Irmak, G., \& Gümüşderelioğlu, M. (2017). A bioprintable form of chitosan hydrogel for bone tissue engineering. Biofabrication, 9(3). https://doi.org/10.1088/17585090/aa7b1d

31. Zhang, Y., Zhou, D., Chen, J., Zhang, X., Li, X., Zhao, W. (2019). Biomaterials Based on Marine Resources for 3D Bioprinting Applications. Marine drugs, $\quad 17(10)$, 555. https://doi.org/10.3390/md17100555

32. Ashammakhi, N., Ahadian, S., Xu, C., Montazerian, H., Ko, H., Nasiri, R., . . . \& Khademhosseini, A. (2019). Bioinks and bioprinting technologies to make heterogeneous and biomimetic tissue constructs. Materials Today Bio,

https://doi.org/10.1016/j.mtbio.2019.100008

33. Şendemir, A. Ü., Seçkin, U. D., Görgün, C., \& Uyanıkgil, Y. (2018). Deri Doku Mühendisliği Üç Boyutlu Biyobask1 ve Keratinosit Kültürü. Dicle Medical Journal, 45(1), 9-18. https://doi.org/10.5798/dicletip.363931

34. Pati, F., Jang, J., Ha, D. H., Won Kim, S., Rhie, J. W., Shim, J. H., . . \& \& Cho, D. W. (2014). Printing three-dimensional tissue analogues with decellularized extracellular matrix bioink. Nature communications, 5. https://doi.org/10.1038/ncomms4935

35. Ahn, G., Min, K. H., Kim, C., Lee, J. S., Kang, D., Won, J. Y., . . \& \& Shim, J. H. (2017). Precise stacking of decellularized extracellular matrix based 3D cell-laden constructs by a 3D cell printing system equipped with heating modules. Scientific reports, 7(1). https://doi.org/10.1038/s41598-01709201-5 
36. Kim, S. H., Yeon, Y. K., Lee, J. M., Chao, J. R., Lee, Y. J., Seo, Y. B., . . . \& Park, C. H. (2018). Precisely printable and biocompatible silk fibroin bioink for digital light processing 3D printing. Nature Communications, 9(1). https://doi.org/10.1038/s41467-018-03759-y

37. Dessane, B., Smirani, R., Bouguéon, G., Kauss, T., Ribot, E., Devillard, R., . . \& \& Crauste-Manciet S. (2020). Nucleotide lipid-based hydrogel as a new biomaterial ink for biofabrication. Scientific Reports, 10(1). https://doi.org/10.1038/s41598020-59632-w

38. Kim, J. H., Kim, I., Seol, Y. J., Ko, I. K., Yoo, J. J., \& Atala, A. (2020). Neural cell integration into 3D bioprinted skeletal muscle constructs accelerates restoration of muscle function. Nature communications, 11(1). https://doi.org/10.1038/s41467-020-14930-9

39. Li, Z., Huang, S., Liu, Y., Yao, B., Hu, T., Shi, H., . . \& \& Fu, X. (2018). Tuning Alginate-Gelatin Bioink Properties by Varying Solvent and Their Impact on Stem Cell Behavior. Scientific Reports, 8(1). https://doi.org/10.1038/s41598-018-26407-3

40. Ji, S., \& Guvendiren, M. (2017). Recent Advances in Bioink Design for 3D Bioprinting of Tissues and Organs. Frontiers in bioengineering and biotechnology, $5, \quad 23$. https://doi.org/10.3389/fbioe.2017.00023

41. Gopinathan, J., \& Noh, I. (2018). Recent trends in bioinks for 3D printing. Biomaterials research, 22: 11. https://doi.org/10.1186/s40824-018-0122-1

42. Hacioglu, A., Yilmazer, H., \& Ustundag, C. (2018). 3D Printing for Tissue Engineering Applications. Politeknik Dergisi, 21(1), 221-227. https://doi.org/10.2339/politeknik.389596

43. Chimene, D., Lennox, K. K., Kaunas, R. R., \& Gaharwar, A. K. (2016). Advanced Bioinks for 3D Printing: A Materials Science Perspective. Annals of Biomedical Engineering, 44(6), 2090-2102. https://doi.org/10.1007/s10439-016-1638-y
44. Liu, J., Sun, L., Xu, W., Wang, Q., \& Yu, S. (2018). Current advances and future perspectives of 3D printing natural-derived biopolymers. Carbohydrate Polymers, 207, 297-316. https://doi.org/10.1016/j.carbpol.2018.11.077 